\title{
Bilateral morphea en coup de sabre: a rare presentation of linear morphea
}

\section{Obustronna twardzina typu en coup de sabre - rzadka postać twardziny linijnej}

Hania Qamar Khan, Mohammad Adil, Syed Suhail Amin, Mohd Mohtashim, Roopal Bansal, Fatima Tuz Zahra

Department of Dermatology, Jawaharlal Nehru Medical College, Aligarh Muslim University, Aligarh, India

Klinika Dermatologii, Jawaharlal Nehru Medical College, Aligarh Muslim University, Aligarh, Indie

Dermatol Rev/Przegl Dermatol 2021, 108, 59-66

DOI: https://doi.org/l0.5। |4/dr.2021. 105896

\section{CORRESPONDING AUTHOR/ ADRES DO KORESPONDENCJI: Mohammad Adil \\ Department of Dermatology Jawaharlal Nehru Medical College Aligarh Muslim University Aligarh, India tel.: 918171169131 e-mail: dr.mohd.adil@gmail.com}

\begin{abstract}
Morphea en coup de sabre is a type of linear localized scleroderma, characterized by a sclerotic skin band in the forehaead and frontoparietal scalp area. It can cause cicatricial alopecia, when affecting the scalp. The disease is mostly unilateral and may be associated with neurological complications and eye defects. Herein, we present a case of bilateral morphea en coup de sabre in a young man, which developed following trauma to the head in childhood 10 years earlier. It produced linear bands of alopecia over the scalp and right eyebrow. The lesions progressed over 4 years, then remained quiescent for 6 years and then restarted progressing again. The patient also complained of repeated frontal headaches but the neurological and ocular examination was normal. Dermoscopy and histopathology were used to confirm the diagnosis. The case is unique because of the bilateral manifestation, preceding trauma and recurrence of disease activity.
\end{abstract}

\section{STRESZCZENIE}

Twardzina linijna typu en coup de sabre (fr. cięcie szablą) ma postać podłużnej, stwardniałej zmiany skórnej umiejscowionej w okolicy czołowo-ciemieniowej, która może się przyczynić do łysienia bliznowaciejącego. Choroba zazwyczaj występuje jednostronnie i mogą jej towarzyszyć zmiany neurologiczne oraz zaburzenia widzenia. W pracy przedstawiono przypadek obustronnej twardziny linijnej typu en coup de sabre, która rozwinęła się u młodego mężczyzny po urazie głowy doznanym 10 lat wcześniej. W następstwie urazu u pacjenta pojawiły się liniowe pasma łysienia na skórze głowy i w obrębie prawej brwi. Zmiany rozwijały się 4 lata, a następnie przez 6 lat były nieaktywne. Ponowna progresja nastąpiła 3 miesiące przed zgłoszeniem się do poradni. Pacjent poinformował również o nawracających bólach głowy w okolicy czołowej, ale badanie neurologiczne i okulistyczne nie wykazało nieprawidłowości. Rozpoznanie potwierdzono na podstawie wyników badania dermoskopowego i histopatologicznego. Opisany przypadek jest szczególny ze względu na obustronną lokalizację zmian, uraz poprzedzający ich wystąpienie oraz nawrót choroby po okresie braku aktywności.

Key words: linear morphea, linear scleroderma, en coup de sabre, scarring alopecia.

Słowa kluczowe: twardzina ograniczona linijna, twardzina ograniczona, en coup de sabre, łysienie bliznowaciejące. 


\section{INTRODUCTION}

Linear morphea is a form of localized scleroderma which accounts for about $15-20 \%$ of adult and $42-67 \%$ cases of childhood morphea [1]. Morphea en coup de sabre (ECDS) is a distinct subtype of linear morphea characterized by a linear sclerotic band and skin discoloration of the frontoparietal scalp. It is almost always unilateral, with very few cases of bilateral ECDS morphea published in the literature. Reactivation of the disease is also rarely reported. We present an interesting case of bilateral morphea ECDS which developed following trauma to the head with progression of lesions after an apparent quiescent period of 6 years.

\section{CASE REPORT}

A 22-year-old male presented to us with complaints of linear depressions over the forehead and scalp with patchy loss of hair for 10 years. There was a history of fall and blunt trauma to the head 6 months prior to onset of lesions. The patient first noticed a red coloured streak on the left side of the forehead that began to spread upwards onto the scalp. Gradually the streak darkened and produced a depression with loss of hair at the involved site. This was followed by similar lesions on the right side of the forehead and scalp after 1 year. The patient gave a history of frontal headaches for the past 5 years. The headaches were moderate to severe in intensity, with 3-4 episodes per week, occasionally associated with irritability and poor sleep. There were no prodromal symptoms and the headache did not meet the International Classification of Headache Disorders (ICHD) criteria for migraine. The lesions had been stationary for 6 years, but for last 3 months, they have been progressing downwards towards eyebrows resulting in patchy alopecia of the right eyebrow.

Physical examination revealed two bilaterally symmetrical fronto-parietal linear sclerotic plaques of $7 \mathrm{~cm}$ length and $2 \mathrm{~cm}$ width, extending obliquely from the medial half of eyebrows to the parietal scalp laterally (fig. 1). Two bilaterally symmetrical linear bands of cicatricial alopecia were seen extending from the parietal scalp medially to vertex (fig. 2). Alopecia was also observed at the middle of the right eyebrow. Skin was fixed to the underlying structures. We were unable to pinch the skin on both plaques. Ocular, auditory and neurological examination was normal except for myopia for the last 8 years for which he used corrective lenses. His vision was $6 / 6$ with glasses.

Dermoscopy of the scalp in the affected area revealed structureless white beams suggestive of fibrosis and single vellus hair (fig. 3). Skin biopsy from the plaque on the right side $2 \mathrm{~cm}$ above the middle

\section{WPROWADZENIE}

Twardzina linijna odpowiada za około 15-20\% przypadków twardziny ograniczonej u osób dorosłych i 42-67\% przypadków u dzieci [1]. Szczególnym podtypem twardziny linijnej jest twardzina en coup de sabre (ECDS). Cechą charakterystyczną tej postaci choroby jest występowanie w okolicy czołowo-ciemieniowej podłużnej, stwardniałej zmiany skórnej z towarzyszącym przebarwieniem. ECDS zazwyczaj występuje jednostronnie. W literaturze jest bardzo niewiele prac opisujących przypadki obustronnej lokalizacji zmian. Rzadko obserwuje się również reaktywację choroby. Przedstawiamy przypadek obustronnej twardziny ograniczonej typu ECDS, która rozwinęła się po urazie głowy. Po 6-letnim okresie braku widocznej aktywności choroby u pacjenta doszło do progresji zmian.

\section{OPIS PRZYPADKU}

Dwudziestodwuletni mężczyzna zgłosił się ze zmianami w postaci zagłębień o podłużnym kształcie umiejscowionymi na czole i owłosionej skórze głowy oraz z nadmierną utratą włosów. Zmiany pojawiły się u pacjenta 10 lat wcześniej. Sześć miesięcy przed ich wystąpieniem mężczyzna doznał tępego urazu głowy na skutek upadku. Najpierw zauważył czerwoną smugę po lewej stronie czoła, która następnie rozprzestrzeniła się na owłosioną skórę głowy. Z czasem smuga ściemniała, a w obrębie zmiany pojawiło się zagłębienie oraz ognisko łysienia. Po upływie roku podobne zmiany wystąpiły po prawej stronie czoła i owłosionej skóry głowy. Pacjent zgłosił także bóle głowy w okolicy czołowej występujące $\mathrm{z}$ częstością 3-4 razy w tygodniu w czasie ostatnich 5 lat. Mężczyzna określił ból jako umiarkowany do silnego. Sporadycznie napadom bólu głowy towarzyszyła drażliwość i obniżenie jakości snu. U pacjenta nie występowały objawy prodromalne, a ból głowy nie spełniał kryteriów migreny określonych w Międzynarodowej Klasyfikacji Bólów Głowy (International Classification of Headache Disorders ICHD). Zmiany skórne pozostawały nieaktywne przez 6 lat, ale w czasie 3 miesięcy poprzedzających wizytę zaczęły się powiększać w kierunku brwi, wywołując ognisko łysienia w obrębie prawej brwi.

$\mathrm{W}$ badaniu przedmiotowym stwierdzono zmiany skórne w postaci stwardniałych blaszek umiejscowione obustronnie symetrycznie $\mathrm{w}$ okolicy skroniowo-ciemieniowej, o długości $7 \mathrm{~cm}$ i szerokości $2 \mathrm{~cm}$. Zmiany przebiegały ukośnie od połowy brwi aż do bocznej części okolicy ciemieniowej (ryc. 1). Zaobserwowano również dwa podłużne pasma łysienia bliznowaciejącego zlokalizowane obustronnie symetrycznie od okolicy ciemieniowej do szczytu głowy 


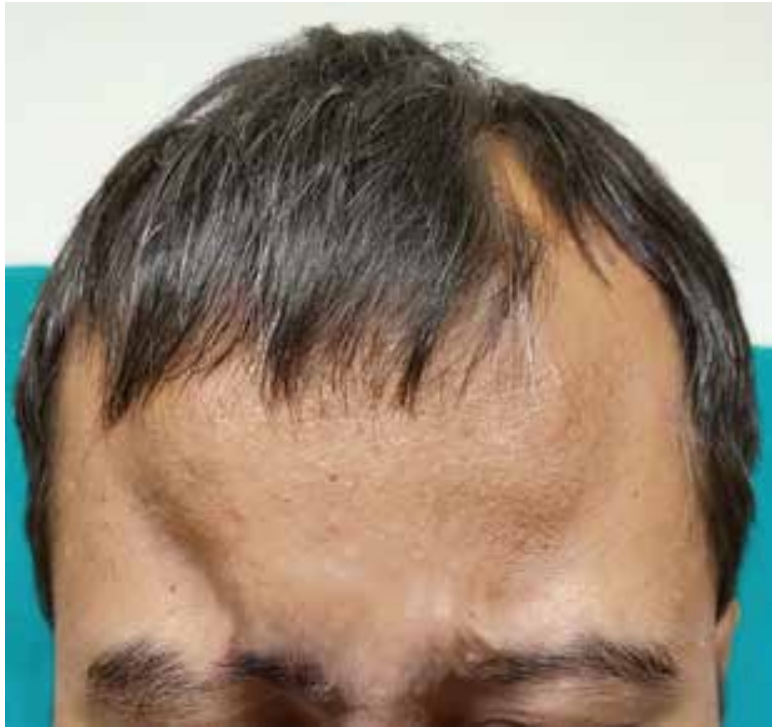

Figure I. Bilateral frontoparietal en coup de sabre morphea more marked on the right side of the forehead with alopecia at the middle of the right eyebrow

Rycina I. Obustronna twardzina ograniczona typu en coup de sabre w okolicy czołowo-ciemieniowej, bardziej nasilona po prawej stronie, z ogniskiem łysienia w środkowej części prawej brwi

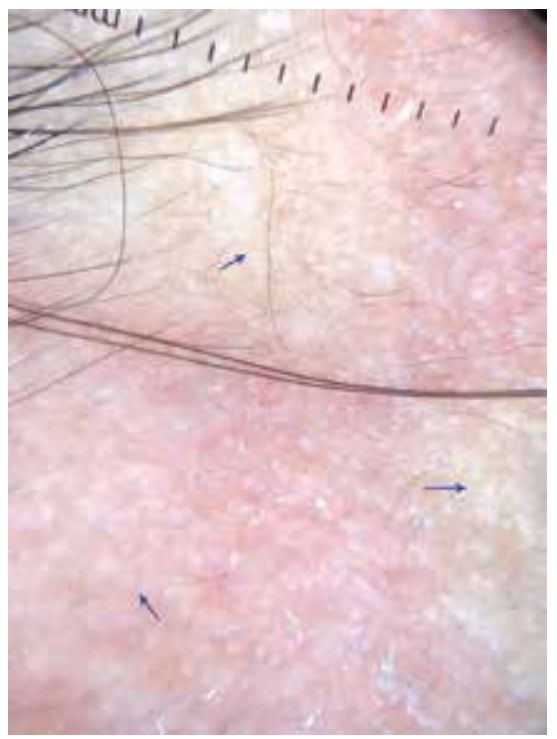

Figure 3. Dermoscopy shows structureless white fibrotic beams (blue arrows) and single vellus hair in the alopecia patch (Dermlite 4; I0X, polarized mode)

Rycina 3. Obraz dermoskopowy z widocznym obszarem bezstrukturalnym w postaci białych zwłókniałych linii (niebieskie strzałki) oraz pojedyncze włosy meszkowe w obrębie ogniska łysienia (Dermlite 4; powiększenie 10×, tryb spolaryzowany)

of the right eyebrow showed keratinized squamous epithelium with underlying dermis showing thickened collagenous bundles with scanty inflammatory infiltrate (fig. 4). Electroencephalogram, radiograph of the skull and magnetic resonance imaging brain revealed no abnormality. The antinuclear antibodies

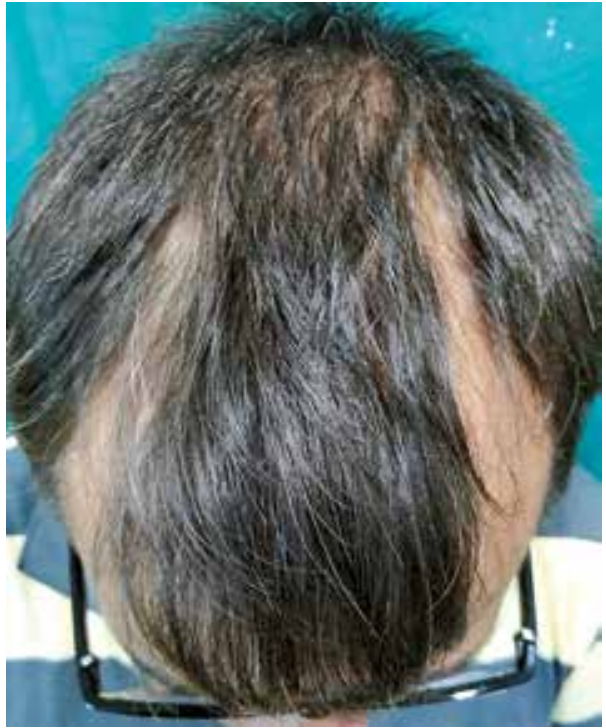

Figure 2. Bilaterally symmetrical linear bands of cicatricial alopecia extending from the fronto-parietal region to vertex

Rycina 2. Podłużne pasma łysienia bliznowaciejącego rozciągające się obustronnie symetrycznie od okolicy czołowo-ciemieniowej do szczytu głowy

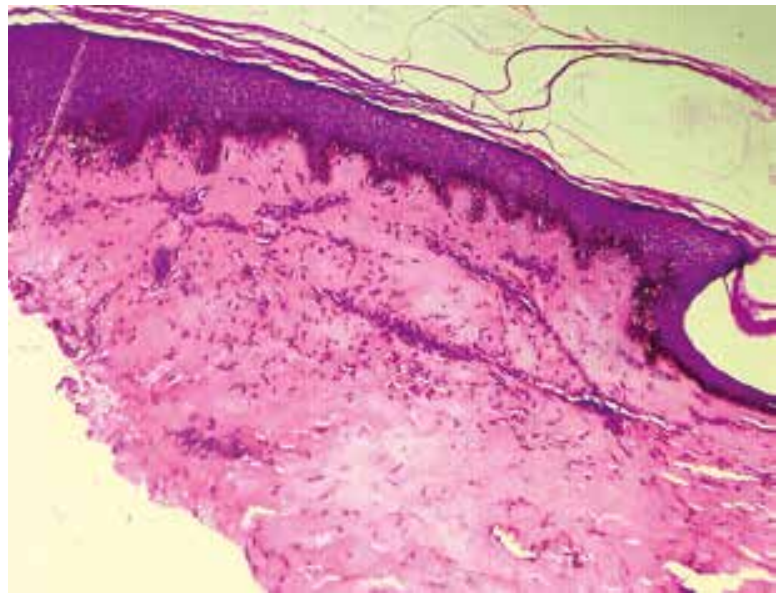

Figure 4. Histopathology of skin biopsy taken from the plaque on the right side showed keratinized squamous epithelium with underlying dermis showing thickened homogenous collagen bundles and scant inflammatory infiltrate $(\mathrm{H}+\mathrm{E} ; \mathrm{IO} \times)$

Rycina 4. Obraz histopatologiczny wycinka skóry pobranego z ogniska po prawej stronie wykazuje obecność rogowaciejącego naskórka, a w leżącej poniżej skórze właściwej pogrubione, jednorodne wiązki włókien kolagenowych i skąpy naciek zapalny (barwienie $\mathrm{H}+\mathrm{E}$; powiększenie $\mathrm{IO} \times$ )

(ryc. 2). Kolejne ognisko łysienia było widoczne na prawej brwi. Skóra była ściśle związana z leżącymi poniżej tkankami - skóry nie można było ująć w fałd. Wyniki badania narządu wzroku i słuchu oraz ocena neurologiczna były prawidłowe. Jedynym odchyleniem od normy była krótkowzroczność rozpoznana 
(ANA) was negative. Our patient was prescribed topical $0.1 \%$ tacrolimus ointment twice daily and intralesional steroids injections in indurated plaques every 3 weeks, and is on regular follow-up.

\section{DISCUSSION}

En coup de sabre morphea usually begins in childhood and involves the paramedian fronto-parietal area in a blashkoid pattern. Although the specific aetiology of morphea is not understood, several triggering factors have been observed in susceptible individuals which include trauma, injections, mechanical compression etc. An association of neurologic symptoms with linear scleroderma ECDS has been well established. They typically occur several years after the onset of ECDS morphea [2]. Neurological involvement most commonly manifests as complex partial seizures. Other features observed are hemiparesis, muscle weakness, personality changes, intellectual deterioration, and headaches [2]. Although our patient had no overt neurological or ocular defects, he did complain of recurrent frontal headaches.

Usually the active stage of disease subsides and remission occurs 3-5 years after the disease onset. However recurrences have been reported in few studies. In a study by Mertens et al. in their study of a large cohort of 344 patients showed that the disease recurrence was present in $27 \%$ of the paediatric-onset group and $17 \%$ of the adult-onset group $(p=0.037)$ [3]. Recurrence was present in median of 26 months (range: 8 months - 26 years) after remission. The highest recurrence rates were present in the linear morphea of the limbs (31\%) and in the mixed subtype $(39 \%)$, whereas the scleroderma ECDS showed recurrence rates of 7\% [3]. A case of ECDS morphea was reported by Arif and Majid in which the lesion remained stationary for 12 years, before recurrence [4]. In our patient, the lesions showed recurrence after remaining apparently quiescent for 6 years.

Very few cases of bilateral en coup de sabre have been reported. After extensive search of the literature, the cases reported previously have been compiled in table 1. Two patients had neurological complications in the form of psychomotor seizures [5], 1 patient showed spikes with dysrhythmia on EEG [6], and facial nerve and oculomotor nerve palsy was described in another case report [7]. Three of 8 cases had associated Parry Romberg syndrome [7-9].

Various therapeutic modalities including topical tacrolimus, phototherapy, calcipotriol in combination with betamethasone dipropionate, imiquimod, methotrexate in combination with systemic steroids, photophoresis, D-penicillamine, etc. have been suggested for ECDS morphea [10], but are not fully satisfactory. Previously reported cases of bilateral ECDS morphea
8 lat wcześniej i leczona za pomocą soczewek korekcyjnych. Ostrość wzroku z korekcją wynosiła 6/6.

Badanie dermoskopowe owłosionej skóry głowy ujawniło obszar bezstrukturalny w postaci białych linii wskazujących na zwłóknienie, a także pojedyncze włosy meszkowe (ryc. 3). Analiza wycinka pobranego do badania histologicznego po prawej stronie ( $2 \mathrm{~cm}$ nad środkową częścią prawej brwi) wykazała obecność zrogowaciałego naskórka. W położonej poniżej warstwie skóry właściwej zidentyfikowano pogrubione wiązki włókien kolagenowych oraz skąpy naciek zapalny (ryc. 4). Badania elektroencefalograficzne, rentgenograficzne czaszki oraz rezonans magnetyczny mózgu nie ujawniły nieprawidłowości. Nie stwierdzono obecności przeciwciał przeciwjądrowych. Pacjentowi przepisano maść z takrolimusem $0,1 \%$ do stosowania miejscowo na skórę 2 razy na dobę. Oprócz tego co 3 tygodnie pacjentowi podawano steroidy w postaci iniekcji doogniskowych (w miejsca stwardniałych blaszek). Chory poddawany jest regularnym badaniom kontrolnym.

\section{OMÓWIENIE}

Twardzina ograniczona linijna typu en coup de sabre zazwyczaj pojawia się w dzieciństwie, obejmując przyśrodkowy obszar czołowo-ciemieniowy z przebiegiem wzdłuż linii Blaschko. Mimo że etiologia twardziny ograniczonej nie jest poznana, zaobserwowano, że chorobę mogą wywołać określone czynniki, m.in. uraz, iniekcje, ucisk mechaniczny itp. Istnieje również potwierdzona zależność między twardziną linijną typu ECDS a rozwojem objawów neurologicznych. Zazwyczaj pojawiają się one kilka lat po wystąpieniu twardziny ograniczonej typu ECDS [2]. Objawy neurologiczne najczęściej mają postać złożonych napadów padaczkowych częściowych. Obserwuje się jednak również niedowład połowiczy, osłabienie mięśni, zaburzenia osobowości, osłabienie zdolności intelektualnych i bóle głowy [2]. U opisywanego pacjenta nie stwierdzono jawnych zaburzeń neurologicznych i nieprawidłowości narządu wzroku, ale skarżył się na nawracające bóle głowy w okolicy czołowej.

W przebiegu twardziny ograniczonej typu ECDS faza aktywna zwykle ustaje, a po 3-5 latach od pojawienia się choroby następuje remisja. W kilku publikacjach opisywano jednak przypadki nawrotów. W badaniu Mertens i wsp. przeprowadzonym w dużej grupie obejmującej 344 pacjentów nawrót wystąpił u 27\% pacjentów, u których choroba pojawiła się w dzieciństwie, oraz u 17\% w grupie o początku choroby $w$ wieku dorosłym $(p=0,037)$ [3]. Nawrót nastąpił po średnio 26 miesiącach (przedział: 8 miesięcy - 26 lat) od remisji. Najwyższe wskaźniki nawrotów odnotowano w twardzinie linijnej kończyn 


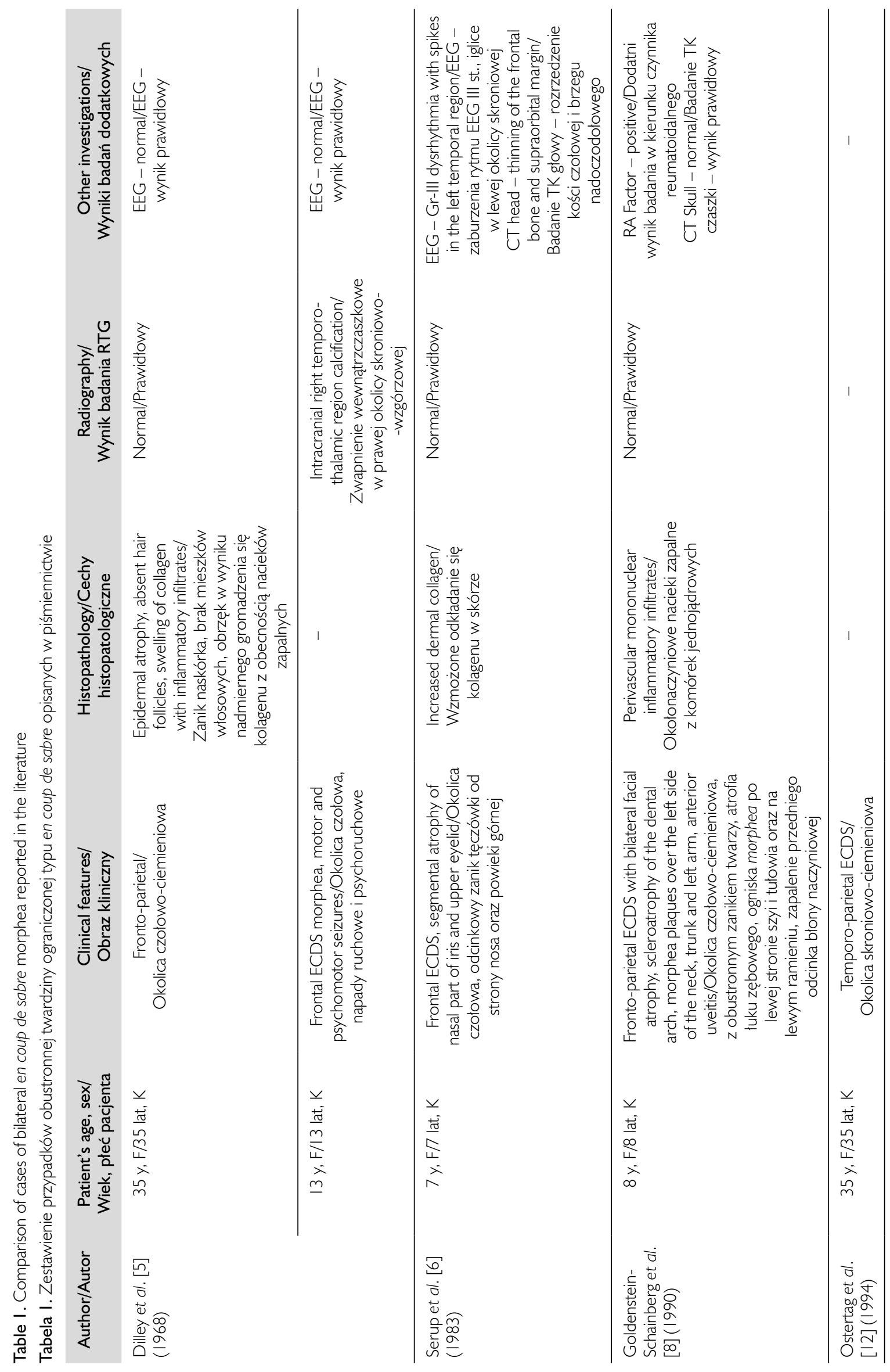




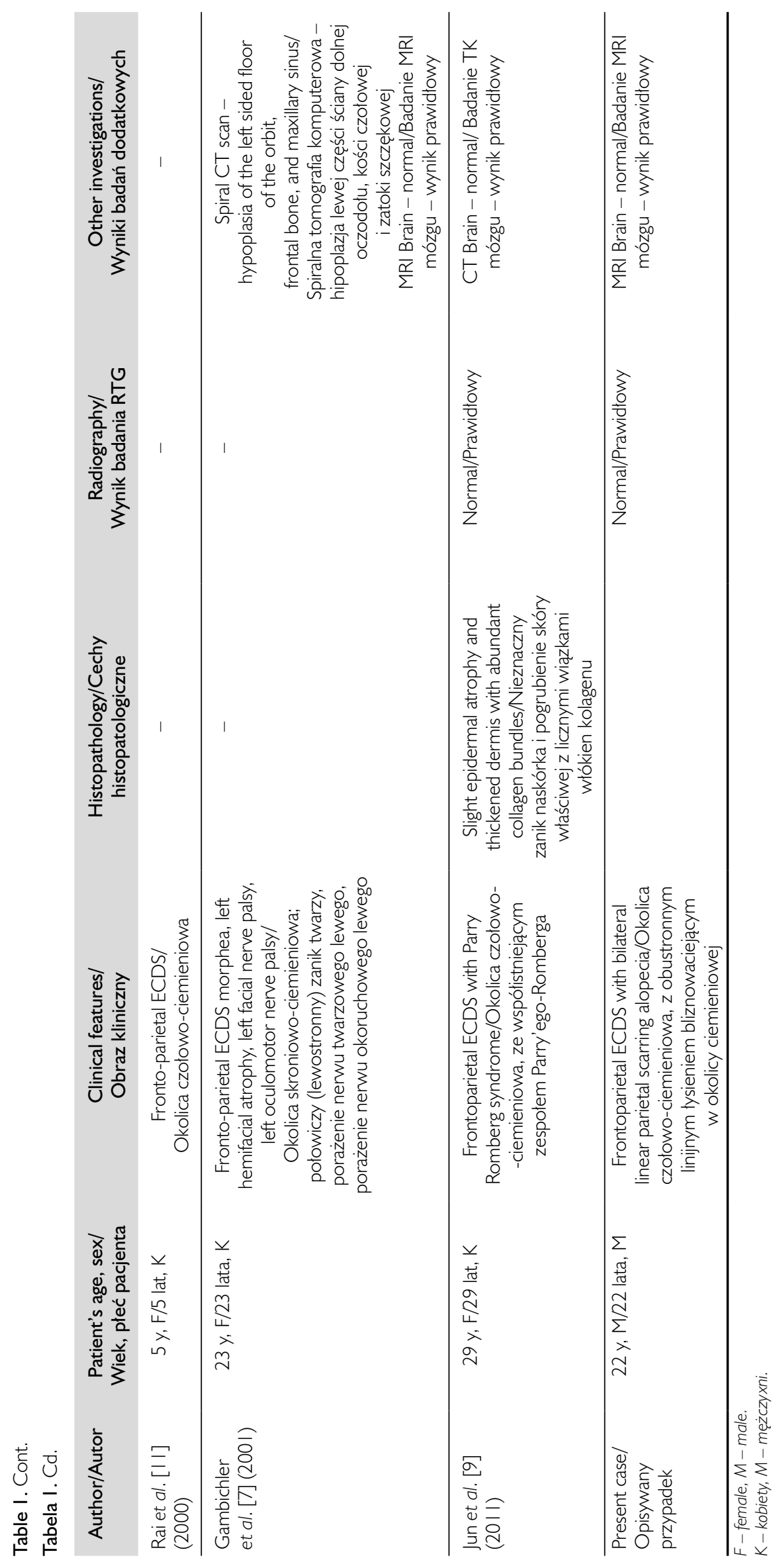


have used D-penicillamine [5, 8], topical corticosteroids $[7,9,11]$, intralesional steroids [9], topical tacrolimus [4], oral mini-pulse prednisolone $20 \mathrm{mg}$ [11] and oral azathioprine [8].

\section{CONCLUSIONS}

We present here an extremely rare case of bilateral morphea ECDS following trauma to the head with recurrence of the disease activity. Patients with morphea ECDS should be followed up for progression of the lesion, development of new plaques, facial atrophy or development of different types of morphea at other body areas as reported by Goldenstein-Schainberg et al. [8]. Patients should be on regular follow-up for neurological, auditory and visual assessment as well.

\section{CONFLICT OF INTEREST}

The authors declare no conflict of interest.
(31\%) oraz w podtypie mieszanym (39\%), natomiast w przypadku twardziny typu ECDS wskaźnik nawrotów wynosił 7\% [3]. W pracy Arifa i Majida opisano przypadek twardziny ograniczonej typu ECDS, w którym nawrót nastąpił po 12-letniej remisjij [4]. U naszego pacjenta nawrót odnotowano po 6 latach braku widocznej aktywności choroby.

W piśmiennictwie można znaleźć tylko nieliczne prace dotyczące obustronnej twardziny ograniczonej typu ECDS. Przypadki zidentyfikowane na podstawie dostępnych źródeł literaturowych zestawiono w tabeli 1. U 2 pacjentów występowały powikłania neurologiczne $\mathrm{w}$ postaci napadów psychoruchowych [5]. Jeden pacjent wykazywał zaburzenia rytmu w EEG [6], a w innym opisie przypadku wśród powikłań wymieniono porażenie nerwu twarzowego i nerwu okoruchowego [7]. W 3 z 8 opisanych przypadków u pacjentów stwierdzono współwystępowanie zespołu Parry'ego-Romberga [7-9].

W leczeniu twardziny typu ECDS stosuje się m.in.: miejscowo takrolimus, fototerapię, kalcypotriol w skojarzeniu z dipropionianem betametazonu, imikwimod, metotreksat w skojarzeniu z glikokortykosteroidami ogólnie, fotoforezę, D-penicylaminę [10], jednak żadna $\mathrm{z}$ tych metod nie daje w pełni zadowalających efektów. W dotychczas opisanych przypadkach obustronnej twardziny typu ECDS $\mathrm{w}$ leczeniu historycznie stosowano D-penicylaminę $[5,8]$, glikokortykosteroidy podawane miejscowo $[7,9,11]$ lub doogniskowo [9], miejscowo takrolimus [4], prednizolon $20 \mathrm{mg}$ doustnie $\mathrm{w}$ postaci krótkich pulsów [11] oraz azatioprynę [8].

\section{WNIOSKI}

W niniejszej pracy przedstawiliśmy wyjątkowo rzadki przypadek obustronnej twardziny ograniczonej typu ECDS, która rozwinęła się po urazie głowy, a po okresie braku aktywności choroby nastąpił jej nawrót. Jak wskazują Goldenstein-Schainberg i wsp. pacjenci $\mathrm{z}$ twardziną typu ECDS powinni być monitorowani pod kątem progresji zmiany, pojawiania się nowych ognisk lub rozwoju innych typów twardziny w innych lokalizacjach [8]. Chorzy wymagają również regularnych badań kontrolnych narządu wzroku i słuchu oraz oceny neurologicznej.

\section{KONFLIKT INTERESÓW}

Autorzy nie zgłaszają konfliktu interesów. 


\section{References}

\section{Piśmiennictwo}

1. Zulian F., Athreya B.H., Laxer R., Nelson A.M., Feitosa de Oliveira S.K., Punaro M.G., et al.: Juvenile localized scleroderma: clinical and epidemiological features in 750 children. An international study. Rheumatology 2006, 45, 614-620.

2. Amaral T.N., Peres F.A., Lapa A.T., Marques-Neto J.F., Appenzeller S.: Neurologic involvement in scleroderma: a systematic review. Semin Arthritis Rheum 2013, 43, 335-347.

3. Mertens J.S., Seyger M.M., Kievit W., Hoppenreijs E.P.A.H., Jansen T.H.TA., van de Kerkhof P.C.M., et al.: Disease recurrence in localized scleroderma: a retrospective analysis of 344 patients with paediatric- or adult-onset disease. Br J Dermatol 2015, 172, 722-728.

4. Arif T., Majid I.: Can lesions of 'en coup de sabre' progress after being quiescent for a decade? Iran J Dermatol 2015, 18, 77-79.

5. Dilley J.J., Perry H.O.: Bilateral linear scleroderma “en coup de sabre" - 2 case reports. Arch Dermatol 1968, 97, 688-689.

6. Serup J., Alsbirk P.H.: Localised scleroderma "en coup de sabre" and iridopalpebral atrophy at the same line. Acta Derm Venereol 1983, 63, 75-77.

7. Gambichler T., Kreuter A., Hoffmann K., Bechara F.G., Altmeyer P., Jansen T.: Bilateral linear scleroderma 'en coup de sabre' associated with facial atrophy and neurological complications. BMC Dermatol 2001, 1, 9.

8. Goldenstein-Schainberg C., Pereira R.M., Gusukuma M.C., Messina W.C., Cossermelli W.: Childhood linear scleroderma 'en coup de sabre' with uveitis. J Pediatr 1990, 117, 581-584.

9. Jun J.H., Kim H.Y., Jung H.J., Lee W.J., Lee S.J., Kim D.W., et al.: Parry-Romberg syndrome with en coup de sabre. Ann Dermatol 2011, 23, 342-347.

10. Fett N., Werth V.P.: Update on morphea. Part II: Outcome measures and treatment. J Am Acad Dermatol 2011, 64, 231-242.

11. Rai R., Handa S., Gupta S., Kumar B.: Bilateral en coup de sabre - a rare entity. Pediatr Dermatol 2000, 17, $222-224$.

12. Ostertag J.U., Hulsmans R.F., Neumann H.A.: Bilateral linear temporoparietal scleroderma "en coup de sabre." Hautarzt 1994, 45, 398-401.

Received: 17.02 .2020

Accepted: 31.08 .2020

Otrzymano: $17.02 .2020 \mathrm{r}$

Zaakceptowano: $31.08 .2020 \mathrm{r}$. 